\title{
Elimination of Arsenic (III) using Phaseolus Lunatus and Phaseolus Vulgaris as Natural Coagulants
}

\author{
Vijayarani. A, Sailaja. B. B. V, Sirisha. D
}

\begin{abstract}
In this analysis, the efficacy of adding coagulants such as Phaseolus lunatus and Phaseolus vulgaris (polymers) to the coagulation process during the treatment of arsenic aqueous solution to extract the arsenic metal was investigated. Experiments were carried out to evaluate the output of Phaseolus lunatus and Phaseolus vulgaris, both individually and in combination with arsenic, using the standard Jar test protocol. P.lunatus and P.vulgaris were given doses ranging from 1 to 3 gm. For P.lunatus and P.vulgaris, the (optimal) removal efficiency for total arsenic in the aqueous solution was obtained at $2 \mathrm{gm}$. With chemical affinity between arsenic and coagulants used in this process, the valence state of arsenic may affect removal efficiency during the chemical coagulation process. $\mathrm{pH}$ is discovered to be a significant factor that has a direct or indirect impact on results. By overcoming the isoelectric point, the complex formed by the interaction of the inorganic pollutant and organic coagulant may aid in the removal of arsenic at pH 9 and 8. P.lunatus and P.vulgaris had optimised arsenic initial concentrations of $57.1 \mu \mathrm{g} / \mathrm{L}$ and $42.6 \mu \mathrm{g} / \mathrm{L}$, respectively. The coagulation mechanism is more prevalent in water treatment, as shown by the above findings.
\end{abstract}

Keywords: Coagulation, Phaseolus lunatus, Phaseolus vulgaris, polymers, isoelectric point.

\section{INTRODUCTION} world (Chen. H.W, Frey. M.M, 1999; Smedley.P.L, and Kinniburgh.D.G, 2002).According to WHO guidelines, the arsenic level in water does not exceed $10 \mu \mathrm{g} / \mathrm{L}$ for human consumption (World Health Organization, 1993). The leakage of arsenic from industrial effluents may be to blame for human health problems. Even though the exact amount of arsenic pollution in our Hyderabad research areas is unknown, there is no denying that this is a serious issue.

Manuscript received on July 02, 2021.

Revised Manuscript received on July 05, 2021.

Manuscript published on August 30, 2021.

* Correspondence Author

Vijayarani.A*, Scholar, Department of inorganic and analytical chemistry, Andhra University. St.Ann's Degree college for women, Mehdipatnam, Hyderabad School, T.S, India. Email: sr.vijayarani.allam@gmail.com

Dr. Sailaja.B.B.V, Head, Department of Inorganic and Analytical Chemistry, Andhra University, Visakhapatnam (Andhra Pradesh), India. Email: sailajabbv.chem@gmail.com

Dr. Sirisha.D, Head, Centre for the Environment and Climate Change, school of Environmental Science, JNIAS, Banjara Hills, Road. No.-12, Kimtee Enclave building, Hyd. T.S. India and St.Ann's Degree College for Women, Mehdipatnam, Hyderabad. Email: sirishadavid@gmail.com

(c) The Authors. Published by Blue Eyes Intelligence Engineering and Sciences Publication (BEIESP). This is an open access article under the CC BY-NC-ND license (http://creativecommons.org/licenses/by-nc-nd/4.0/)
Arsenic is found in water naturally in many parts of the

In Patancheru and Khatedan, removing arsenic from groundwater is a big challenge. In both cases, cost-effective treatment measures that are simple to implement are necessary to reduce arsenic levels in drinking water. Arsenic can be removed from drinking water in a variety of ways. Coagulation is the best available technology for arsenic removal efficiency among these methods (USEPA, 2002). This paper examines the use of enhanced coagulation to remove arsenic from groundwater, which represents a largescale arsenic problem. The aim of this study was to see how effective Phaseolus lunatus and Phaseolus vulgaris are at removing arsenic from aqueous solutions by coagulation. The effect of P.lunatus and P.vulgaris doses, as well as $\mathrm{pH}$, and arsenic concentration on turbidity in treated water was investigated. It was also looked at using a small amount of polyelectrolyte as a coagulant aid. The results of carefully prepared aqueous solutions can be applied to real-world groundwater analysis.

\section{Objectives:}

1. To develop the purification technology with low cost, non-toxic and eco-friendly organic coagulants.

2. To assess the coagulant's adsorption potency and intensity, and refine the coagulant for its effectiveness.

\section{PREPARATION OF NATURAL COAGULANTS}

The removal of arsenic from Phaseolus lunatus and Phaseolus vulgaris seeds was found to be $80 \%$ and $84 \%$ respectively in a screening test. Taking this into account, the seeds of Phaseolus lunatus and Phaseolus vulgaris were collected separately, washed, and dried in the sun before being crushed in an ordinary mixer grinder and passed through a sieve to extract active coagulant. Ranging from 1 to $5 \mathrm{gm}$ of Phaseolus lunatus and Phaseolus vulgaris seed powder were suspended separately in $100 \mathrm{ml}$ of distilled water and stirred for 5 minutes in a centrifuge mixer.

Finally, the suspension was filtered through a tough filter paper, and the resulting filtrate, known as crude extract, was stored separately in the refrigerator for later use (Jelena M., Prodanovic, et al., 2013). Coagulant doses are the amounts of active coagulation agents derived (originated) from 10 , 20 , and $30 \mathrm{mg}$ of seeds in these volumes of extract. Active coagulants in the coagulation-flocculation process are proteins, which are found in P.lunatus and P.vulgaris. The effect of different dosages on arsenic adsorption was studied using these extracts in doses ranging from $1 \mathrm{gm}$ to $5 \mathrm{gm}$.

Published By: Blue Eyes Intelligence Engineering ronongeu
and Sciences Publication (C) Copyright: All rights reserved.

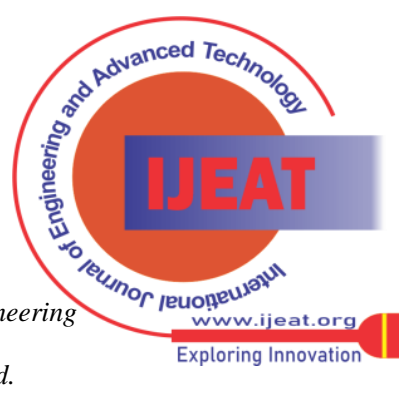




\section{RESULTS AND DISCUSSION}

\section{1: Effect of coagulants dosage:}

One of the most critical parameters in determining the best conditions for coagulant efficiency is the different dosage (extracts) of coagulants in coagulation and flocculation. Bad coagulation outcomes may be caused by an insufficient dosage or overdosing. As a result, deciding the optimum dosage is important in order to minimise the cost of coagulants and sludge formation while achieving the best treatment results. The effect of coagulant dose on arsenic eradication using Phaseolus lunatus and Phaseolus vulgaris was investigated separately using various coagulant dosages at a constant Arsenic concentration of $50 \mu \mathrm{g} / \mathrm{L}$, as shown in Figures 1 and 2, which confirmed that the percentage of arsenic removed increases as the coagulant dose is increased. Each 2gm of P. lunatus dose and P. vulgaris dose could remove $71 \%$ and $68 \%$ of arsenic respectively. The seeds of Phaseolus lunatus and Phaseolus vulgaris are rich in protein and electrically charged possessing the coagulation properties. Arsenic ions bind to proteins rapidly, allowing arsenic ions in water to degrade (J.E. Gregor, C.J. Nokes, et al., 1997).

\subsection{Effect of pH:}

In an aqueous medium, the $\mathrm{pH}$ regulates the solubility of organic matter (Phaseolus lunatus and Phaseolus vulgaris). Coagulant particles usually have a negative charge and are stable at the isoelectric point with the lowest solubility. This prompted researchers to look into the effect of $\mathrm{pH}$ on coagulation behaviour and to find the best $\mathrm{pH}$ for future coagulation experiments. Phaseolus lunatus and Phaseolus vulgaris seeds were used as coagulants in jar test apparatus experiments with a 2 gm extract dosage. In Figs. 3, the initial $\mathrm{pH}$ of the aqueous solution was varied from $\mathrm{pH} 8$ to $\mathrm{pH} 11$ and from $\mathrm{pH} 6$ to $\mathrm{pH} 11$ respectively. At $\mathrm{pH} 9.0$ or higher, both Phaseolus lunatus and Phaseolus vulgaris extracts displayed roughly the same high coagulation activity, as seen in Figures 3. At pH about 7, there is no coagulation operation, and the same low efficiency was observed when distilled Moringa oliefera extract ( Okuda, T., A. U. Baes, et al., 2001) and $\mathrm{Al}^{3+}$ or $\mathrm{Al}^{3++}$ tannin (Özacar, M. and A. Şengil, 2003) were used as coagulants. Further experiments were conducted with $\mathrm{pH} 9.0$ for Phaseolus lunatus and $\mathrm{pH} 8.0$ for Phaseolus vulgaris in this study. The higher the $\mathrm{pH}$, the better the coagulation. This is because:

1. Higher $\mathrm{pH}$ values are better for coagulation since certain extract components are negatively charged at $\mathrm{pH}$ above. This is consistent with our previous research, which found that common bean water extracts had the highest coagulation activity at pH 9 (Okuda, T., A. U. Baes, et al., 2001).

2. Due to turbidity, the presence of charge on the particles prevents them from joining. Since the particles are electrically neutral at the isoelectric point, they clump together and sink to the bottom. Organic material suspensions become more stable as the $\mathrm{pH}$ value moves away from the isoelectric point. As a result, the coagulation activities of P. lunatus and $\mathrm{P}$. vulgaris seed extract were determined at $\mathrm{pH}$ values ranging from 8 to 11 . With the $\mathrm{M}$. oleifera extracts, similar results were obtained (Okuda, T., Baes, A. U, et al., 2001)

\subsection{Coagulant Effects of Initial Chromium Concentration:}

The results of arsenic removal by coagulationflocculation using natural coagulants (Phaseolus lunatus and Phaseolus vulgaris) for different initial concentrations $(20 \mu \mathrm{g} / \mathrm{L}-80 \mu \mathrm{g} / \mathrm{L})$ are shown in Fig-4. The efficiency of arsenic removal increases with increasing the initial concentration of arsenic until $60 \mu \mathrm{g} / \mathrm{L}$ at constant coagulant dose of P. lunatus and P.vulgaris and decreases at higher concentrations, according to these figures. The low availability of active binding sites in the protein content present in these coagulants seed powder is the cause of the decrease in removal quality. Despite their high protein content, arsenic molecules wrap around the proteins, covering the binding sites, as the concentration of arsenic ions rises. As a result, the percentage elimination decreases as the arsenic concentration rises. In this analysis, the optimal arsenic concentrations for P. lunatus and P.vulgaris were $57.1 \mu \mathrm{g} / \mathrm{L}$ for P. lunatus and $46.2 \mu \mathrm{g} / \mathrm{L}$ for P.vulgaris.

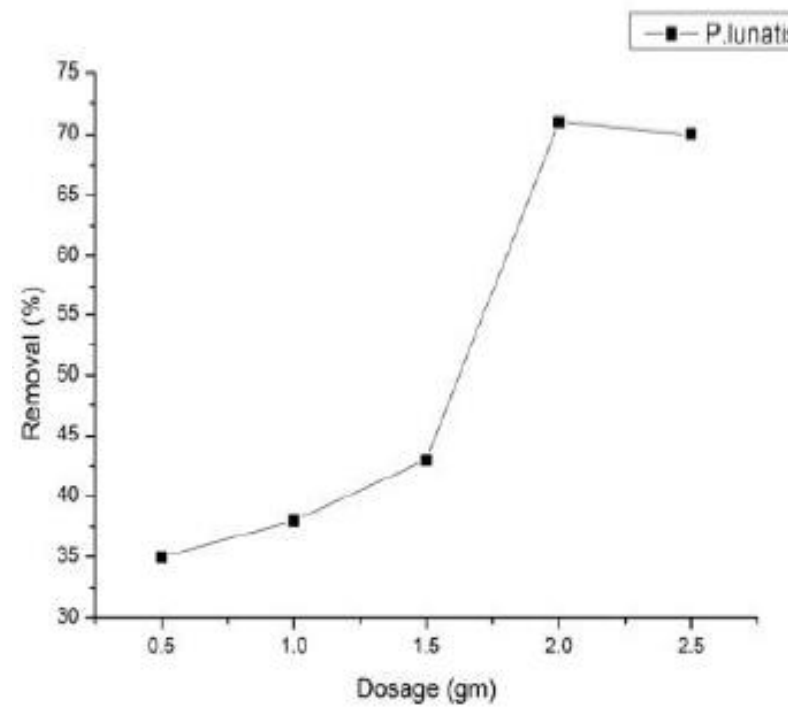

Figure-1: Effect of Phaseous lunatus dosage on Arsenic adsorption

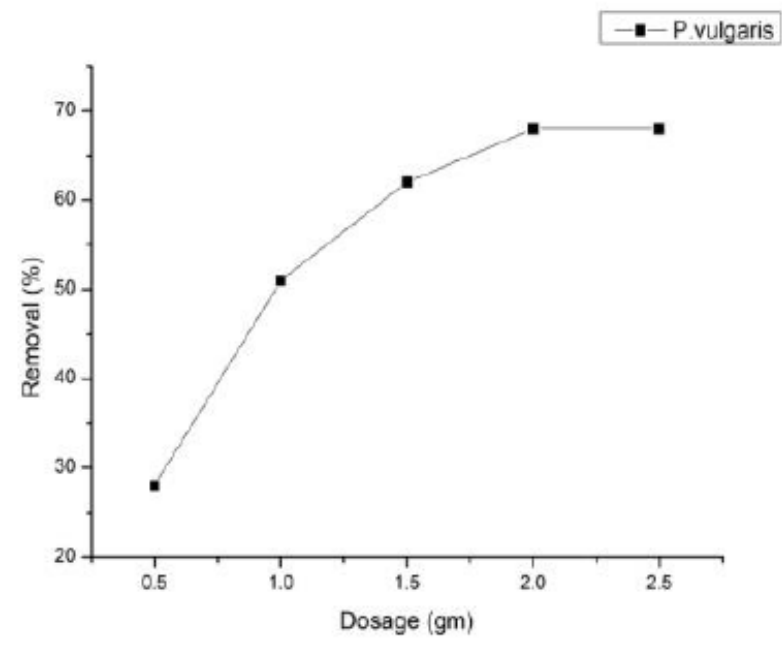

Figure-2: Effect of Phaseolus .vulgaris dosage on Arsenic adsorption 


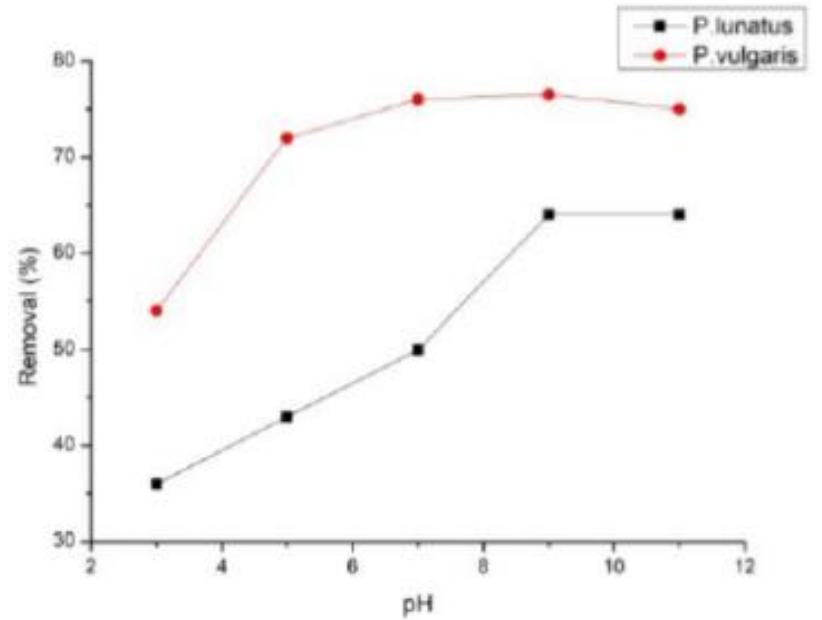

Figure-3: Effect of $\mathbf{p}^{\mathrm{H}}$ on P.lunatus and P.vulgaris for arsenic removal

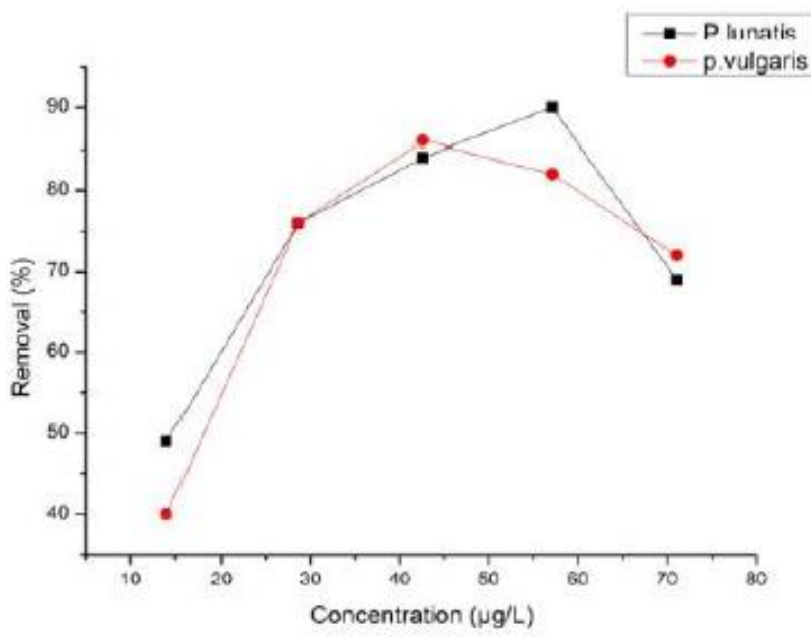

Figure-4: Effect of concentration on P.lunatus and P.vulgaris for arsenic removal

\subsection{Mechanism:}

Coagulation procedures usually involve multiple steps. The coagulant is first applied to the effluent, and mixing is done quickly and thoroughly. The aim is to thoroughly combine the coagulant with the wastewater, enhancing the efficacy of particle destabilisation and initiation of coagulation. A second stage occurs, during which flocculation will last up to 30 minutes. The suspension is slowly stirred at this point to increase interaction between coagulating particles and promote the formation of large flocs. While the clarified effluent overflows, the flocs are transferred to a clarification basin, where they settle and are collected from the bottom.

\section{There are two types of mechanisms:}

1. The protein in the coagulant seed functions as a cationic polyelectrolyte in this coagulation analysis. The soluble particles in the water bind to the active agent, forming large flocs in the water. Because of the composition of the coagulants (polyelectrolyte) and arsenic, this process involves physical and chemical interactions at the molecular level. By exposing contaminants to an electrophoretic effect, the coagulation-flocculation mechanism is suggested, to test the dosage, $\mathrm{pH}$ calculation and chemical affinity as parameters for determining the electrostatic and chemical interaction between pollutants and polyelectrolyte.

2. Colloids or particles in water have a charge, which is affected by $\mathrm{pH}$ for certain organisms. The formation of the well-known electrical double layer around the particles is caused by this charge. The well-known Derjaguin-LandauVerwey-Overbeek (DLVO) theory describes particle stability due to electrical double layer interactions, and the electrical forces prevent the particles from getting near enough for the physical attractive forces to draw and keep them together. Coagulants can enmesh polluted particles in water by forming charged intermediates that adsorb at the particle surface, reducing the charge and thickness of the electrical double layer (charge neutralisation) (P.Huck, M. Sozariski, 2011).

\section{CONCLUSION}

The natural coagulants Phaseolus lunatus and Phaseolus vulgaris were studied for its efficiency in removal of arsenic from aqueous solution by considering the influencing parameters such as coagulant dose, $\mathrm{pH}$, and initial arsenic concentration. The optimum condition for maximum arsenic removal was achieved as: $\mathrm{pH} 9$ for Phaseolus lunatus and $\mathrm{p}^{\mathrm{H}}$ 8 for Phaseolus vulgaris, same dosage of $2 \mathrm{mg}$ for both coagulants. The maximum percentage removal of arsenic was found to be $88 \%$, and $90 \%$ for Phaseolus lunatus, and Phaseolus vulgaris respectively at initial arsenic concentrations. It is evident from the results that the natural coagulants Phaseolus lunatus and Phaseolus vulgaris are equally efficient in removal of arsenic from aqueous solution.

\section{Conflict of Interest:}

No conflicts of interest regarding this manuscript.

\section{ACKNOWLEDGEMENT}

I am in gratitude to my guide Dr.B.B.V.Sailaja, head of the Department of Inorganic and Analytical Chemistry at Andhra University, and my co-guide Dr.D.Sirisha David, whose passion, experience, and meticulous attention to detail have been an inspiration and kept my work on track since my first encounter with this paper, and would not have been possible without their help. I'm also greatful to St.Ann's Degree College for Women in Mehdipatnam, Hyderabad, for allowing me to complete my lab project in the college's research lab.

\section{REFERENCES}

1. H.W. Chen, M.M. Frey, D. Clifford, L.S. McNeill and M. Edwards, Arsenic treatment considerations, J. AWWA, 1999, 91: 74-85.

2. P.L. Smedley and D.G. Kinniburgh, A review of the source, behaviour and distribution of arsenic in natural waters, Appl. Geochem., 2002, 17: 517-568.

3. USEPA, Technologies and Costs for Removal of Arsenic from Drinking Water, EPA/815/R-00/028, Washington, 2000.

4. Guidelines for Drinking Water Quality, Vol. 2: Health Criteria and other Supporting Information, 2nd ed., World Health Organization, Geneva, Switzerland, 1993.

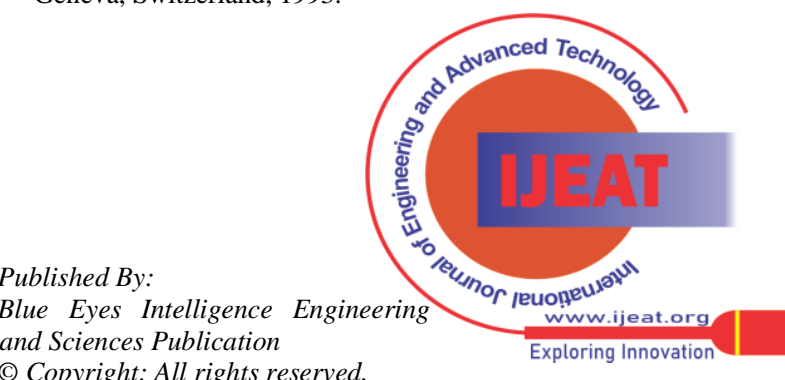


5. C.T. Driscoll, RD Letterman: Factors regulating residual aluminium concentrations in treated waters. Environmetrics 1995, 6: 287-309. 10.1002/env.3170060306

6. M. Jelena, Prodanovic, Mirjana, G.,Antov, B.Marina, Sciban, B.Bojana, Ikonic, V.Dragana, , Kukic, M.Vesna, Z.Vasic Darjana, Ivetic, Desalination and Water Treatment, 2013:51, 1.

7. J.E. Gregor, C.J. Nokes, E. Fenton, Optimising Natural Organic Matter Removal from Low Turbodity Waters by Controlled $\mathrm{pH}$ Adjustment of Aluminum Coagulant, Water Res. 1997:31, $2949-$ 2958.

8. T. Okuda, A. U. Baes, W. Nishijima and M. Okada: Isolation and characterization of coagulant extracted from Moringa oleifera seed by salt solution. Wat. Res: 2001, 35, 2 :405 - 410.

9. M.Özacar, and A. Sengil: Evaluation of tannin biopolymer as coagulant aid for coagulation of colloidal particles. Colloids and Surfaces A: Physicochem. Eng.Aspects. 2003, 22985 - 96.

10. T. Okuda, A.U. Baes, W. Nishijma, and M.Okada, Improvement of extraction method of coagulation active components from Moringa oleifera seed Water Res. 2001, 33 (15), 3373 - 3378.

11. P.Huck, M. Sozariski, in Treatise on water science, Aquatic Chemistry and Biology, 2011.

Table-1: Chemical composition of coagulants

\begin{tabular}{|c|c|c|c|}
\hline S.No & Parameters & $\begin{array}{l}\text { Phaseolus } \\
\text { lunatus } \\
\text { Composition } \\
\text { in \% }\end{array}$ & $\begin{array}{l}\text { Phaseolus } \\
\text { vulgaris } \\
\text { Composition } \\
\text { in \% }\end{array}$ \\
\hline 1. & Moisture & 7.40 & 11.75 \\
\hline 2. & Protein & 22.63 & 26.72 \\
\hline 3. & Fat & 3.49 & 0.94 \\
\hline 4. & Crude fibre & 6.45 & 21.20 \\
\hline 5. & Ash & 4.75 & 4.34 \\
\hline 6. & Carbohydrates & 55.28 & 68.0 \\
\hline
\end{tabular}

\section{AUTHORS PROFILE}
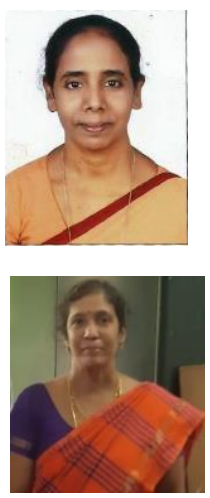

A. Vijayarani, completed M.Sc in Chjemistry in Nagarjuna University, Guntur, A.P. in 2004-2006. Present. she is pursuing P.hD in Environmental Chemistry as part time in Andhra University under the guidance of Dr. B.B.V.Sailaja and co-guidance of Dr.D.Sirisha. chemical properties of oxalato and malonato complexes of uranium (VI)

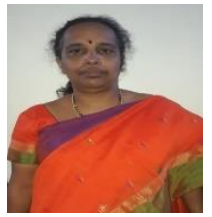

Dr. D. Sirisha, Head, Centre for environment and climate change, school of environmental sciences, Jawaharlal Nehru Institute of advanced studies. She had completed her Ph. D from JNTUH, Hyderabad in the year 2006. Principal investigator and coinvestigator for SUGC projects IDBT and NCERT-2 and DST-2 research projects. 94 research papers were published under her guidance. She guided one scholar to complete Ph.D. Present 5 scholars from various universities are pursuing $\mathrm{Ph} . \mathrm{D}$ under her guidance. She is working as a research advisor in St. Ann's College for Women, Hyderabad.

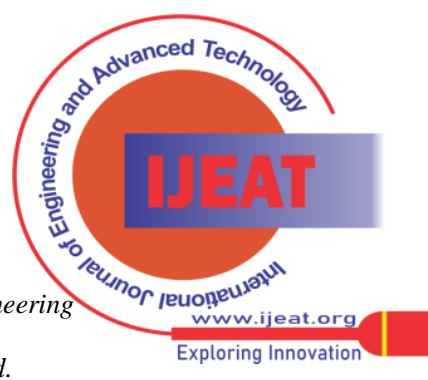

